\title{
Hospitalidade, Competitividade e Stakeholders de Eventos Empresariais - Estudo de Casos em Bourbon Hotéis e Resorts (Brasil)
}

\section{Hospitality, Competitiveness and Stakeholders of Corporate Events - The Case Study in Bourbon Hotels and Resorts (Brazil)}

\author{
Alan Aparecido Guizi (GUIZI, A. A.) ${ }^{*}$ e \\ Elizabeth Kyoko Wada (WADA, E. K.) ${ }^{* *}$
}

RESUMO - O crescimento da quantidade de viagens corporativas destacada pelo Ministério do Turismo (BRASIL, 2015), e o impacto que esse segmento provoca na hotelaria em especial para hospedagem de eventos corporativos, levantou a seguinte problemática de pesquisa: As relações baseadas em hospitalidade com stakeholders, seria um diferencial competitivo na atração e realização de eventos corporativos em Bourbon Hotéis e Resorts? Por meio desta problemática, estabeleceu-se como objetivo geral, identificar se as relações baseadas em hospitalidade com stakeholders, seria um diferencial competitivo na atração e realização de eventos corporativos em Bourbon Hotéis e Resorts. Neste estudo de característica qualitativa-exploratória, se utilizou como método o estudo das referências bibliográficas em artigos, livros, dissertações, documentos online, matérias de mídia, e, com base em Yin (2010), a realização de entrevistas com roteiros semiestruturadas os quais foram aplicados a gerentes gerais dos hotéis escolhidos da rede Bourbon Hotéis e Resorts. Em conclusão, observou-se que o relacionamento com stakeholders estava garantindo o fortalecimento de parcerias, que resultavam na aquisição de novos clientes para realização de eventos, gerando não só recursos financeiros, como também o fortalecimento do nome da rede no mercado.

Palavras-chave: Hospitalidade; Serviços; Stakeholders; Eventos Corporativos; Competitividade.

ABSTRACT - The growing amount of corporate travel, highlighted by the Tourism Department (BRAZIL, 2015), and the impact that this segment has in hotel industry especially for hosting corporate events, it is proposed the following research problem: The relationships based on hospitality with stakeholders, would be a competitive differential in attracting and hosting corporate events in Bourbon Hotels and Resorts? Therefore, the general goal of this study was "identify if the relationships based on

\footnotetext{
* Formação: Graduação em Turismo pela Universidade Anhembi Morumbi (UAM), Especialização Lato Sensu em Estratégias de Marketing e Vendas pela Fundação Escola de Comércio Álvares Penteado (FECAP) e Mestrado em Hospitalidade pela Universidade Anhembi Morumbi. Atividade profissional: Professor do curso de bacharelado em Turismo, Escola de Turismo e Hospitalidade da Universidade Anhembi Morumbi. Endereço físico para correspondência: Rua Itupava, 72. CEP: 80045-140 - Curitiba Paraná (Brasil). E-mail: alanguizi@gmail.com

** Formação: Graduação em Turismo pelo Centro Universitário Ibero Americano (UNIBERO) e Graduação em Relações Públicas pela Universidade de São Paulo (USP); Especialização Lato Sensu em Administração Mercadológica pela Fundação Getúlio Vargas (FGV); Mestrado e Doutorado em Ciências da Comunicação pela Universidade de São Paulo (USP). Pós-doutorado em Turismo pela Universidade Federal do Paraná (UFPR). Atividade profissional: Professora, coordenadora e pesquisadora do PPG Stricto Sensu - Mestrado e Doutorado - em Hospitalidade da Universidade Anhembi Morumbi. Endereço profissional: Rua Casa do Ator, 294 - $7^{\circ}$ andar. CEP: 04546-001 - São Paulo - São Paulo (Brasil). Email: ewada@uol.com.br
} 
hospitality with stakeholders would be a competitive advantage in attracting and hosting corporate events in Bourbon Hotels and Resorts. This qualitative-exploratory study, used references from articles, books, dissertations, online documents, media materials, and based on Yin (2010), interviews with semi-structured scripts which were applied to general managers of the hotels chosen from Bourbon Hotels and Resorts. In conclusion, it was observed that the relationship with stakeholders was ensuring the strengthening of partnerships, which resulted in the acquisition of new customers for events, creating not only financial resources, but also the strengthening of the hotel name in the market.

Key words: Hospitality; Services; Stakeholders; Corporate events; Competitiveness. 


\section{INTRODUÇÃO}

O presente estudo partiu da observação de dados que apontaram para o crescimento em 400\% no número de viagens de negócios entre 2003 a 2013, sendo o segundo segmento que mais atrai turistas estrangeiros ao Brasil, respondendo por 25,3\% dos turistas internacionais, cujo gasto médio diário se situou em US\$ 102,18 - 50\% a mais que turistas de lazer (BRASIL, 2015). Tal crescimento em viagens corporativas representa significativo valor estratégico para a hotelaria, visto que a utilização de sua infraestrutura para hospedagem de executivos e realização de eventos empresariais são fatores que contribuem na diminuição dos efeitos da sazonalidade.

Tais números indicam a influência da globalização e a queda de fronteiras quando o assunto é a busca por novos mercados e representação de empresas em outros lugares, considerando-se não apenas viagens dentro de um país, mas também para outros países do globo, cujas atividades envolvem o encontro entre profissionais em eventos empresariais, assistências técnicas, entre outras negociações pertinentes.

É importante destacar que a atividade de turismo de negócios, ou mobilidade corporativa, envolve não apenas o turista, mas, uma série de outros stakeholders que, conforme Freeman (1984) são indivíduos, grupos ou empresas que influenciam ou são influenciados em todas as atividades e objetivos de pessoas e empresas onde, neste estudo, é compreendida pelas atividades de viagens corporativas, cuja gestão do relacionamento com stakeholders visa maximizar efeitos positivos e minimizar os negativos, resultando na superação de expectativas de viagem do turista.

Com isso, estabeleceu-se como problemática de pesquisa a seguinte questão: As relações baseadas em hospitalidade com stakeholders seria um diferencial competitivo na atração e realização de eventos corporativos em Bourbon Hotéis e Resorts? Possíveis proposições foram levantadas e, com a evolução do estudo, foram testadas: P1) O relacionamento com stakeholders prepara uma empresa para compreender o que estes valorizam bem como o que valorizarão, permitindo atendê-los, antes que sua concorrência a faça; P2) O relacionamento entre hotel e empresas interessadas na realização de eventos empresariais é o único fator que envolve competitividade, não havendo intermediários; P3) Apenas o relacionamento com stakeholders envolvidos na realização dos eventos é considerado fator de competitividade. 
Por meio da problemática estabelecida, o objetivo geral de estudo foi: Identificar se as relações baseadas em hospitalidade entre Bourbon Hotéis e Resorts e seus stakeholders, seria um diferencial competitivo na atração e realização de eventos corporativos. Portanto, os objetivos específicos de pesquisa foram: a) conhecer os stakeholders relevantes, segundo hoteleiros entrevistados, para hospedagem de eventos corporativos; b) compreender como a hospitalidade tornava-se diferencial competitivo no relacionamento entre pessoas; c) estudar a competitividade sob a visão da hotelaria.

\subsection{MÉTODO}

Este artigo trata da apresentação de resultados de pesquisa, cuja primeira etapa foi exposta no XI Seminário da Associação Nacional de Pesquisa e Pós-Graduação em Turismo - ANPTUR de 2014, na cidade de Fortaleza (Estado do Ceará) no Grupo de Trabalho: Hospitalidade em Empresas (GUIZI, FARIA, WADA, 2014).

Nesta pesquisa de característica qualitativa-exploratória se utilizou como método, em primeira etapa, o estudo dos conceitos escolhidos por meio de livros, artigos, documentos online e dissertações, para organização do presente artigo nas seguintes seções: Hospitalidade e competitividade; Gestão do relacionamento com stakeholders; Mobilidade corporativa e os eventos empresariais.

A segunda etapa de estudo consistiu em estudo de casos que, conforme Yin (2010) é baseado em um protocolo de pesquisa que previu a escolha de objetos de estudos para análise, sendo, então, escolhida a rede Bourbon de Hotéis e Resorts, mais especificamente as unidades hoteleiras Bourbon Atibaia Convention \& Spa Resort (Atibaia, São Paulo, Brasil) e, Bourbon Cataratas Convention \& Spa Resort (Foz do Iguaçu, Paraná, Brasil).

Nestas unidades foram realizadas visitas técnicas e entrevistas com seus respectivos gerentes gerais, José Ozanir Castilhos (Bourbon Atibaia C\&SR) e Osvaldo Júlio Neto (Bourbon Cataratas C\&SR), utilizando-se roteiro de entrevista semiestruturado, categorizando-se os temas que seriam discutidos em "resultados de eventos corporativos", "principais fatores de atração de eventos", "infraestrutura hoteleira" e "stakeholders de eventos corporativos". 
Destaca-se que, na categoria de stakeholders de eventos corporativos, buscou-se por meio da participação dos gerentes gerais entrevistados, a criação conjunta de uma figura, ou como especificado em Freeman (1984), de um mapa que revelasse os stakeholders da rede hoteleira que atendessem aos eventos corporativos, e que portanto, detém a atenção da rede para gestão de relacionamento, além de parcerias e atenção.

Durante as entrevistas, os gerentes gerais contatados assinaram um termo permitindo a divulgação do conteúdo obtido e de seus nomes em trabalhos científicos. Essas entrevistas foram gravadas e posteriormente transcritas para interpretação, tendo como base o marco teórico apresentado neste artigo.

Por fim, os resultados e conteúdo obtido em entrevistas e visitas técnicas aos resorts escolhidos, foram apresentados por meio do tema, Competitividade na atração de eventos corporativos na hotelaria: Estudo de casos nos hotéis Bourbon, validando-se a teoria frente a realidade observada por meio do método de emparelhamento (LAVILLE; DIONNE, 1999, p. 228).

Em considerações finais, apresenta-se o alcance dos objetivos propostos, assim como a resposta à problemática de pesquisa e análises de proposições frente o conteúdo obtido em entrevistas e marco teórico. Por fim, apresentam-se sugestões para futuros estudos no campo da mobilidade corporativa e hospitalidade com stakeholders na hotelaria.

\section{HOSPITALIDADE E COMPETITIVIDADE}

A hospitalidade, segundo Camargo (2004), é a atividade de recepcionar, hospedar, alimentar e entreter pessoas temporariamente deslocadas de sua origem que, por meio dela é possível criar um relacionamento ainda inexistente ou, reforçar aquele já existente, essa prática busca ultrapassar a interação imediata, e assegurar a reciprocidade (GOTMAN, 2001; SELWYN, 2004).

Lashley (2000), por sua vez, aponta para domínios onde as atividades de hospitalidade transcorrem (FIGURA 1). Esses domínios descrevem os rituais ou as atividades realizadas segundo cada contexto de hospitalidade, conforme as descrições a seguir (LASHLEY, 2000): 
- Domínio social: A hospitalidade em cidades, espaços públicos, ou em comunidades, o ato de recepcionar o visitante por meio do estreitamento de laços, rituais ou costumes para agregar o outro em uma nova comunidade já existente;

- Doméstica: Caracteriza-se pelo recebimento do outro na residência de seu anfitrião, ficando a cargo desse, as atividades de recepcionar, hospedar e alimentar o visitante, levando-se em conta os costumes da residência e de sua família;

- Comercial: Baseia-se nas relações de oferta e demanda de mercado, onde o relacionamento entre pessoas está baseado nas relações de serviços, e sacrifício monetário.

No entanto, Lashley (2000) ressalta que somente com a intersecção dos 3 domínios citados, faz-se possível administrar as experiências de hospitalidade considerando-se, portanto, o desejo de agregar o outro em uma nova comunidade como em domínio social, permitindo que o outro participe de suas tradições, seus costumes e seu cotidiano como em domínio doméstico, porém sem perder o rigor de um serviço como em domínio comercial.

Para exemplificar essa união, Wada (2007) descreve que é possível sua visualização por meio da hotelaria, onde o domínio social da hospitalidade é observado por aqueles que recepcionam o hóspede, tal como o próprio recepcionista, porteiros, mensageiros e outros, já o domínio privado, na hotelaria, é de responsabilidade daqueles que garantem o conforto do hóspede durante seu período de permanência, como a camareira, os seguranças e os garçons, por sua vez, o domínio comercial refere-se àqueles que respondem pelo setor de controladoria, compras, auditoria, reservas e gerência. 




FIGURA 1 - ATIVIDADES DE HOSPITALIDADE

FONTE: Baseado em Lashley (2000).

A hospitalidade, enquanto contexto comercial busca alavancar a qualidade em serviços e relacionamento, fazendo com que o cliente se sinta em casa durante o período em que está deslocado dela. Esse relacionamento visa fazê-lo sentir-se bem recebido, identificando suas reais necessidades bem como suas expectativas quanto aos serviços que serão realizados. Para isso, a personalização dos serviços é considerada estratégica por meio do conhecimento aprofundado de seus hóspedes, para atender e superar suas expectativas, resultando em sua fidelização (JUNQUEIRA; WADA, 2010)

Bronze Júnior et al. (2012) ressaltam a importância do relacionamento com o cliente para a qualidade em serviços por meio do marketing de relacionamento, o qual definem como responsável pela identificação das necessidades e desejos do públicoalvo, garantindo a satisfação dos mesmos e, por meio dele, os objetivos da organização.

Frederico, Frederico e Oliveira (2005) ressaltam que, por meio da hospitalidade é possível a fidelização de clientes, pois, é por meio dos conceitos de hospitalidade que se adota como cultura empresarial o atendimento generoso e ético, com vistas à personalização de serviços, considerando-se, sobretudo o conforto e bem-estar do cliente, ou hóspede, e não somente envolvendo o interesse monetário e mercantilista.

Stefanini, Yamashita e Sousa. (2012) pontua por meio de suas pesquisas que, dentre os fatores mais relevantes de percepção de valor por clientes corporativos em hotelaria, o atendimento, a presteza, a rapidez no atendimento e, sobretudo a simpatia, 
são pontos mais destacados, tornando-se fator de diferenciação e reconhecimento de um hotel, frente sua concorrência.

Esse reconhecimento das necessidades e expectativas detidas por clientes, levando-os ao encantamento, é descrito por Kim e Mauborgne (2005) como inovação de valor, tornando-se um diferencial competitivo, ditando as fronteiras do mercado e expandindo-a a seu favor, criando o que os autores chamam de oceano azul ${ }^{1}$. Prahalad e Hamel (2005) consideram essa inovação de valor como uma competência essencial para a competitividade, pois é uma performance, ou um desempenho, e por ser um ativo intangível não sofre desgaste com o tempo.

A competência essencial para personalização de serviços é compreendida por meio de Gotman (2009) quando descreve os serviços com marcas de hospitalidade, que envolvem cessão de benefícios, bens ou atenção em pequenos detalhes nos momentos ou em aspectos onde o cliente mais necessita, percebidos por meio do relacionamento com o mesmo.

No entanto, vale destacar que a hospitalidade não envolve somente os princípios do recebimento de visitantes ou de clientes, mas também uma série de costumes de modo a estreitar o relacionamento também com pessoas, grupos e organizações ligadas à empresa, bem como são influenciadas ou influenciam as ações e objetivos da mesma, como abordado na teoria de stakeholders, conforme Freeman (1984), a seguir.

\section{GESTÃO DO RELACIONAMENTO COM STAKEHOLDERS}

Assim como descrito anteriormente, a hospitalidade envolve o relacionamento não só com clientes, como também os esforços para relacionamento com grupos e entidades que igualmente possuem necessidades, expectativas e poderes sobre determinada empresa. Esses grupos, classificados por Freeman (1984) como stakeholders, possuem diferentes interesses acerca das atividades e objetivos dessa empresa dado que afetam, ou são afetados por ela, sendo representados na figura 2 a seguir (FREEMAN, 1984).

\footnotetext{
${ }^{1}$ Oceanos azuis "se caracterizam por espaços de mercado inexplorados, pela criação de demanda e pelo crescimento altamente lucrativo [...]. Nos oceanos azuis, a competição é irrelevante, pois as regras do jogo ainda não estão definidas" (KIM; MAUBORGNE, 2005, p. 4).
} 


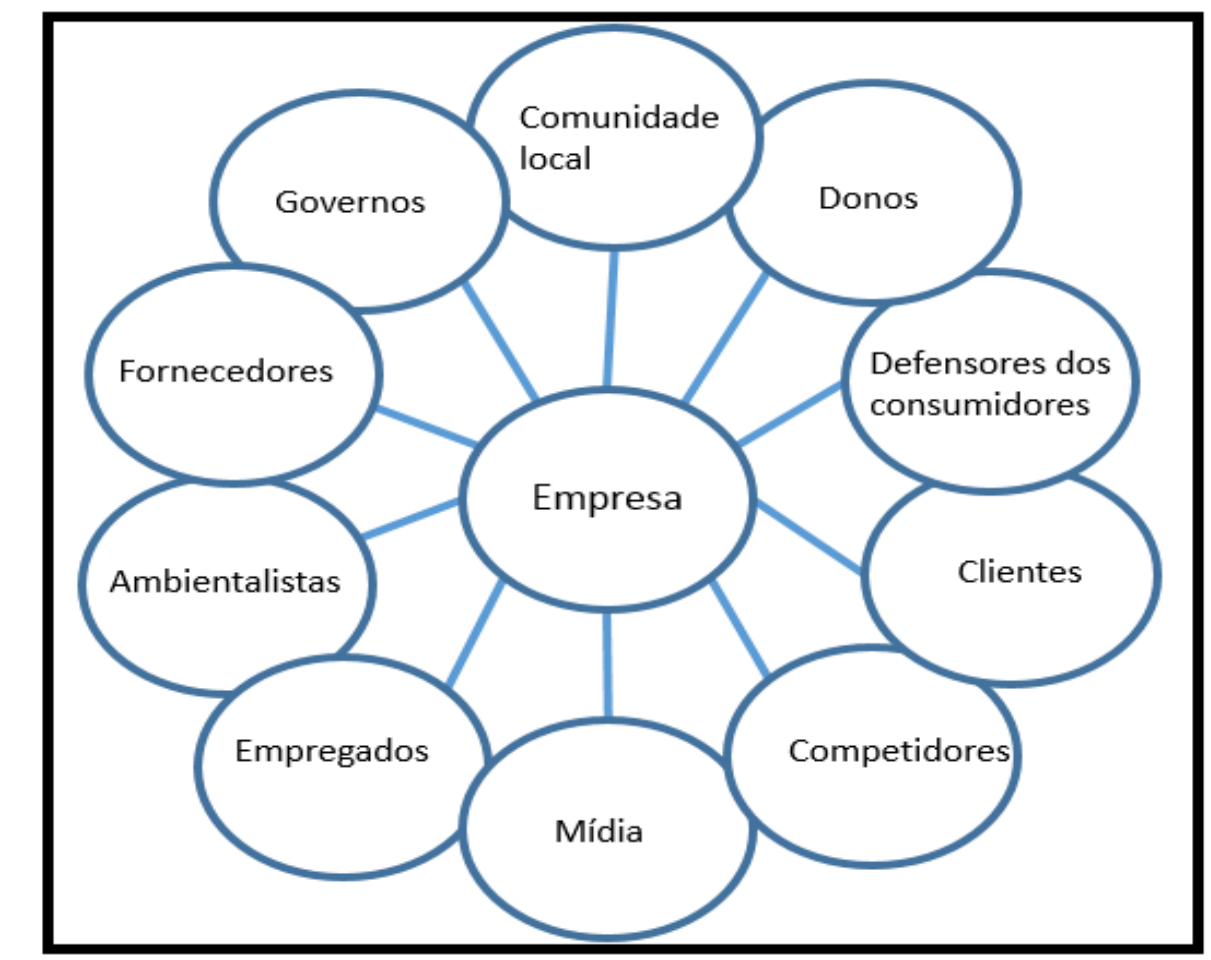

FIGURA 2 - MAPA DOS STAKEHOLDERS

FONTE: Baseado em Freeman (1984).

Por meio da figura 2 nota-se que, assim como as empresas trabalham a favor de clientes para que estes continuem comprando, seu público interior (seus colaboradores) também necessita atenção, pois também são afetados pelas atividades e objetivos dessa empresa resultando, consequentemente, em bom relacionamento com stakeholders de representação de classe, tais como sindicatos e associações. Por sua vez, leva a um bom relacionamento com a comunidade local que, se não atendida ou desrespeitada, possuem o direito de protestar contra a presença da empresa no local, entre outras possibilidades.

O gerenciamento de relacionamento com stakeholders visa conhecer aquilo que é valorizado por estes grupos, indivíduos ou empresas, para que tais valores sejam compreendidos e respeitados por meio de ações, ou somados aos objetos empresariais.

Para isso, Woodruf (1997) propõe o modelo de stakeholder value determination, ou determinação de valor para o stakeholder estabelecido em forma de passo-a-passo para compreensão dessas necessidades e, o que deve ser alterado na empresa de modo que essas necessidades sejam respeitadas, buscando melhorar seu relacionamento com stakeholders, especialmente aqueles considerados estratégicos, antes de sua concorrência. Esse modelo propõe que, a aproximação com seus stakeholders, permite 
que uma empresa conheça aquilo que será valorizado pelos mesmos, antes de seus concorrentes.

Identificar as necessidades de stakeholders visa, sobretudo, estreitar relações em busca do reconhecimento não só de seus clientes, mas também com seus colaboradores, fazendo-os engajarem-se com os objetivos da empresa e tornando-os não só funcionários, mas anfitriões do local onde trabalham, motivando-os ao trabalho, e, que se torne um ciclo de benefícios, onde a satisfação em desempenhar um bom serviço por anfitriões, seja percebido por clientes de modo positivo (GOTMAN, 2009).

Visando o relacionamento mercadológico também com empresas parceiras, o estreitamento de relações busca o trabalho em conjunto, sejam elas fornecedoras de matéria-prima ou de serviços, em busca de benefícios mútuos que esse trabalho possa gerar, seja ele ganho financeiro, ganho de visibilidade e de marca, ou ganho de reputação em mercado (VAN RIEL, 2013).

\section{MOBILIDADE CORPORATIVA E OS EVENTOS EMPRESARIAIS}

Compreende-se por mobilidade corporativa, as viagens realizadas por pessoas com objetivos laborais dentro ou fora do país, cuja finalidade é a representação comercial, fechamento de negócios, participação em eventos, treinamentos, ou assistência técnica em equipamentos (CUNHA, 2001² apud BRAGA, 2006, p. 89).

A organização de viagens desta natureza é realizada por empresas gestoras de viagens (conhecidas em inglês por Travel Management Companies - TMCs), as quais possuem know-how, ou conhecimentos adequados e referências de fornecedores de serviços de turismo para montagem de pacotes, bem como facilidades para meios de pagamento, economizando tempo de empresas-clientes e estabelecendo métodos de controle de gastos e desperdícios, além de maximizar a segurança de seus executivos (WADA, 2009).

Entre as atribuições de empresas gestoras de viagens está o auxílio com vistos e passaportes de executivos, informações acerca da destinação e, se necessários de vacinas, aluguel de automóveis ou fornecimento de outros métodos de mobilidade como

\footnotetext{
${ }^{2}$ CUNHA, L. Introdução ao turismo. Lisboa: Verbo, 2001.
} 
traslados, permitindo que esses cumpram suas agendas de compromissos sem imprevistos (WADA, 2009).

Dentre as motivações de viagens corporativas, os eventos empresariais, ou eventos corporativos, são acontecimentos agendados para reunião pessoas de semelhantes objetivos e interesses, bem como outros stakeholders, para discussão de temas relacionados às suas respectivas atividades profissionais tais como congressos, feiras, workshops, exposições, convenções de vendas, entre outros acontecimentos semelhantes (OLIVEIRA; FONTANA, 2012).

Sob o ponto de vista da hotelaria, eventos corporativos são acontecimentos que promovem o próprio hotel para uma série de pessoas e empresas, favorecendo retornos financeiros e de reconhecimento, dado que a realização desses eventos em suas dependências, torna-se oportunidade também para seus participantes hospedarem-se, contribuindo sobretudo, para o conforto do participante e para "manter os quartos ocupados por mais tempo e afastar o perigo de operar um hotel com alta ociosidade" (ARANHA; MIGUEL, 2013).

\section{COMPETITIVIDADE NA ATRAÇÃO DE EVENTOS CORPORATIVOS NA HOTELARIA: ESTUDO DE CASOS EM HOTÉIS BOURBON}

Com mais de 50 anos de existência, a rede de hotéis e resorts Bourbon, empresa $100 \%$ brasileira, conta com 12 empreendimentos hoteleiros no Brasil, e 2 outros empreendimentos na Argentina e Paraguai (BOURBON, 2016a). É considerada a rede com a maior área de eventos em hotéis do Brasil (H2FOZ, 2013; BOURBON, 2016b), além de maior centro de convenções do Paraguai, dentro do hotel Bourbon Conmebol Asunción Convention Hotel, onde está sediada a Confederação Sul-Americana de Futebol - CONMEBOL (BOURBON, 2016c).

Destaca-se também o empreendimento localizado em Buenos Aires (Argentina), que, segundo Alceu Vezzozo Filho, presidente vigente da rede em entrevista concedida à Revista Hotéis (2013), tratando-se de uma das ações de expansão da bandeira da rede para outros países da América do Sul, mas com o cuidado de não perder a essência de seu atendimento e serviços oferecidos. 
Durante entrevista à Revista Hotéis (2013), o então presidente da rede, o Sr. Alceu Vezozzo Filho, destacou que um dos principais diferenciais de seus hotéis ocorria no modo e na postura de seus funcionários durante atendimento, buscando aproximação com o cliente, porém, sem deixar de lado a formalidade. Para o presidente, o jeito brasileiro de ser e servir seria fazer o cliente sentir-se em casa, e tratando-o de modo amável e cortês, conhecendo-o pelo nome, e estando sempre a sua disposição, compreendidas como ações baseadas em hospitalidade em contexto comercial, permitindo que o hóspede seja integrado à comunidade hoteleira. (REVISTA HOTÉIS, 2013; LASHLEY, 2000).

Esses princípios da rede Bourbon rendeu-lhes o reconhecimento em forma da operacionalização dos serviços de hospedagem da seleção brasileira de futebol, na Granja Comary, cidade de Teresópolis (Rio de Janeiro), durante a Copa do Mundo de Futebol em 2014, sob os cuidados de cerca de 20 profissionais de Bourbon Atibaia, supervisionado pelo então gerente geral, José Ozanir Castilhos da Rosa (PALUMBO, 2014).

Observou-se, durante visitas técnicas realizadas pelos autores em 2014 nas unidades Bourbon Atibaia C\&SR e Bourbon Cataratas C\&SR, que a rede Bourbon prezava por seu relacionamento estreito tanto com hóspedes quanto com seus parceiros estratégicos, sendo eles representantes de empresas e operadoras de turismo, empresas que já realizavam ou, que pudessem vir a realizar eventos corporativos em seus hotéis, ou empresas-clientes para hospedagem de pessoas ou de eventos. Esse cuidado foi ressaltado também por meio de entrevistas concedidas pelos gerentes gerais Osvaldo Júlio Neto e José Ozanir Castilhos, de Bourbon Cataratas C\&SR e Bourbon Atibaia C\&SR respectivamente, aos autores, e apresentados nos próximos parágrafos, visando sobretudo, conhecer o que era valorizado por stakeholders, de modo que fosse respeitado e atendido pela equipe hoteleira, como visto em Woodruff (1997).

Em entrevista, durante a categoria "resultados de eventos corporativos na unidade hoteleira", o então gerente geral de Bourbon Atibaia C\&SR, José Ozanir Castilhos da Rosa afirmou que, anualmente, aproximadamente $60 \%$ dos resultados financeiros do resort eram devido ao fluxo de eventos corporativos, bem como o fluxo de pessoas gerados por meio deste, confirmando Nakane (2010), dado que a realização 
de eventos na hotelaria, afasta os efeitos da sazonalidade, colaborando para que o hotel não seja gerido com quartos vazios.

Nessa mesma entrevista, José Ozanir ressaltou a importância da parceria com outros hotéis da região, considerados também como seus stakeholders diretos pois, em eventos maiores é possível dividir as hospedagens com outros hotéis, considerando-se, portanto, o fator localidade como um diferencial competitivo para hotéis, devido a oferta de diversas opções de serviços complementares na cidade, tais como mobilidade urbana, atrações turísticas, pontos de acesso como aeroportos e rodoviárias, cidades próximas que geram fluxos de pessoas ou influências em negócios que, para Foz do Iguaçu considera-se sua área de fronteira com Argentina e Paraguai e, para Atibaia, sua proximidade com São Paulo, além de opções de gastronomia, hospedagem entre outros serviços.

Também durante entrevista concedida aos autores, na categoria "principais fatores de atração de eventos", o então gerente geral de Bourbon Cataratas C\&SR, Osvaldo Júlio Neto, afirmou que a marca hoteleira era um dos principais fatores de atração de eventos ao hotel, baseada na reputação construída pela rede em estrutura e relacionamento com stakeholders, alcançando seu engajamento conforme abordado em Van Riel (2013).

Acerca da infraestrutura hoteleira voltada para hospedagem de eventos empresariais, Osvaldo Júlio Neto ressaltou a flexibilidade da estrutura de seu hotel para especificações de clientes e empresas parceiras, ressaltando a possibilidade dessa flexibilidade servir-lhes como propaganda espontânea, onde um cliente indicaria aos seus contatos, ou à associação de empresas a qual participa, o espaço de eventos de Bourbon Cataratas C\&SR.

Ainda na categoria "infraestrutura hoteleira”, José Ozanir destacou programas de qualidade, tal como o programa "no capricho" além de softwares que acompanham o funcionamento de equipamentos, que visam minimizar possíveis problemas com equipamentos importantes, e ampliar os cuidados com manutenção de Bourbon Atibaia C\&SR.

Durante as entrevistas, apresentou-se a proposta de construção em conjunto de um mapa de stakeholders, adaptado de Freeman (1984, p. 55), solicitando-se, então, a indicação de seus principais stakeholders que influenciavam ou eram influenciados por 
eventos corporativos realizados em suas respectivas unidades hoteleiras, baseando-se em suas observações e experiência profissional, sendo apresentado na figura 3, a seguir.

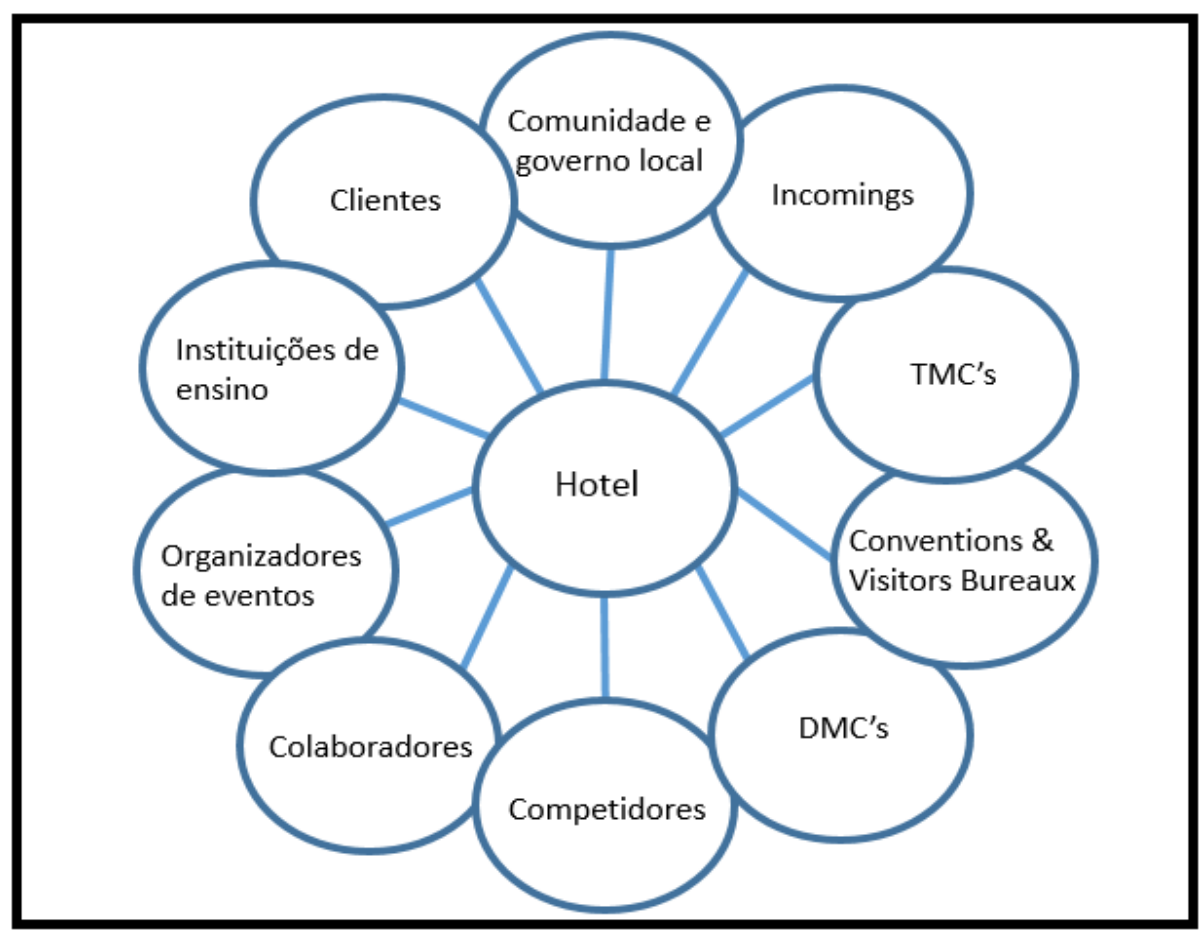

FIGURA 3 - MAPA DOS STAKEHOLDERS, SEGUNDO INDICAÇÕES DOS ENTREVISTADOS FONTE: Adaptado de Freeman (1984, p. 55).

Acerca do mapa cocriado, Osvaldo Júlio Neto, de Bourbon Cataratas C\&SR, enfatizou, por ocasião do evento Bourbon Partners de 2014 para premiação dos principais parceiros da rede, que a gestão do relacionamento com empresas do setor de eventos levava à indicações de seu hotel para outros potenciais parceiros, como empresas organizadoras de eventos, o que facilitava a captação destes tipo de evento ao hotel, dado que as mesmas utilizavam-se de sua lista de empresas-clientes para indicação de espaços para convenções.

Sendo assim, por meio dessas indicações e entrevistas realizadas, notou-se a importância, bem como a quantidade de influenciados e influenciadores aos objetivos da realização de eventos corporativos na rede Bourbon, destacando-se parceiros como as Travel Management Companies, ou Agências Gestoras de Viagens que, como abordado anteriormente, atuavam com a organização de viagens de executivos, e representantes de empresas, de localidades mais distantes daquelas onde seria realizado o evento. 
Foram igualmente mencionadas as DMC's - Destination Marketing Companies, ou Empresas de Marketing de Destinos - e Convention \& Visitor Bureau, as quais eram responsáveis por promover a destinação em outros locais ou cidades, assim como captar eventos para as cidades ou regiões onde os hotéis escolhidos estão instalados.

Os entrevistados citaram também as empresas de incoming, ou de receptivo turístico, que atuavam com a recepção de executivos e ofereciam serviços de transporte entre outras assistências enquanto em destino, para garantir o conforto e segurança de participantes.

Por sua vez, em Schulze (2013) se ressalta a importância da comunidade local, já que esta é alvo não somente dos benefícios, mas também de malefícios trazidos pelo fluxo de pessoas decorrido da atividade turística, tais como produção de lixo, trânsito, filas e outros. O engajamento da comunidade de um local pode influenciar positivamente (ou negativamente) na hospitalidade de visitantes e turistas, o que resulta também na prestação de serviços de outros colaboradores e empresários locais.

Assim como órgãos de governança dos locais onde a atividade turística está presente, engajando-os a trabalhar em apoio do turismo e favorecendo a atração de novos eventos além de novos turistas, por meio de infraestrutura mais adequada para tanto, em transporte, comércio, entre outros aspectos inerentes.

As instituições de ensino foram citadas pelo entrevistado José Ozanir, de Bourbon Atibaia C\&SR, acentuando-se a necessidade da qualificação e preparação de colaboradores para que os serviços pudessem ser, de fato, realizados com a qualidade esperada pela rede, por seus hóspedes, e por parceiros, engajando-os assumir o papel de anfitrião em sua empresa (GOTMAN, 2009).

Nota-se, portanto, a necessidade da compreensão do tema 'hospitalidade', bem como sua inserção nas práticas de relacionamento interpessoal, seja em contexto social ou doméstico, seja em contexto comercial. Ressalta-se a necessidade da hospitalidade, como princípio do relacionamento humano, pois cada empresa ou cada órgão é, sobretudo, formado por pessoas, e o conjunto dessas pessoas por sua vez, resulta em stakeholders de uma empresa, todos com diferentes interesses em ações, objetivos, ou resultados de empresas, assim como ressaltado nos estudos realizados em Bourbon Hotéis e Resorts. 


\section{CONSIDERAÇÕES FINAIS}

O presente estudo teve como intenção a apresentação dos conceitos de hospitalidade como princípio do relacionamento humano, baseado na ética e nos bons costumes, presente em todos os momentos do cotidiano seja em contexto doméstico, social ou comercial, desde que se envolvam pessoas e o desejo de servir, ou de receber o outro em uma nova comunidade.

Destacou-se, sobretudo, que a observação das leis da hospitalidade dita não somente o trato com o visitante, enquanto alguém deslocado de sua origem, mas também com parceiros, ou cujo laço de amizade e parceria já exista, assegurando seu fortalecimento e renovação.

Em meio empresarial, esse relacionamento estimula a criação da reputação em mercado, pois um parceiro indica a seus pares os serviços de uma empresa cujo efeito, neste estudo, buscou-se compreender por meio da rede hoteleira Bourbon Hotéis e Resorts, utilizando-se como método o estudo de casos múltiplos (YIN, 2010) realizando-se visitação técnica e entrevistas com roteiro semiestruturado, contatando-se gerentes gerais das unidades Bourbon Atibaia C\&SR (Atibaia, São Paulo, Brasil) e Bourbon Cataratas C\&SR (Foz do Iguaçu, Paraná, Brasil).

Segmentando-se o estudo da atividade turística em mobilidade corporativa, ou turismo de negócios, buscou-se compreender os stakeholders estratégicos da rede hoteleira, que possibilitassem resultados financeiros, visibilidade em mercado, e parcerias para captação e hospedagem de eventos corporativos, caracterizados pela reunião de pessoas com interesses em comum, para uma série de atividades profissionais programadas.

Portanto, considera-se alcançado o objetivo geral de pesquisa, que propôs identificar se as relações baseadas em hospitalidade entre Bourbon Hotéis e Resorts e seus stakeholders, seria um diferencial competitivo na atração e realização de eventos corporativos.

Observou-se que o relacionamento baseado em hospitalidade com stakeholders além da geração de fluxo de pessoas ao hotel, evitando a operação de quartos vazios, favorecia também a geração de confiança tanto para parceiros, clientes, colaboradores e outros stakeholders. A confiança, a reputação de mercado, a infraestrutura, o atendimento profissional, e o know-how da rede em hospedar eventos, segundo 
observado em entrevistas, é fator determinante considerado, neste estudo, competência essencial para a competitividade da rede em relação à sua concorrência.

Com isso, ratifica-se a primeira proposição de estudo, "o relacionamento com stakeholders prepara uma empresa para compreender o que estes valorizam bem como o que valorizarão, permitindo atendê-los, antes que sua concorrência a faça", pois conforme visto anteriormente em Woodruff (1997), em determinação de valor para o stakeholder, o relacionamento com o mesmo visa conhecê-los, bem como conhecer aquilo que é valorizado, de modo que a empresa se prepare para atendê-los da melhor forma possível, cuja reputação possibilita que esses stakaholders favoreçam a empresa em futuras negociações ou atividades.

Em entrevistas, essa proposição se fez presente por meio do interesse em qualificação constante de seus colaboradores, de modo a torná-los anfitriões de seu ambiente de trabalho (GOTMAN, 2009), compreendendo-se, sobretudo o interesse de stakeholders em dispor de serviços profissionais, porém conforme o lema da empresa, sem deixar o "jeitinho brasileiro" de lado.

A proposição de número 2, “o relacionamento entre hotel e empresas interessadas na realização de eventos empresariais é o único fator que envolve competitividade, não havendo intermediários", foi negada, pois como visto no mapa de stakeholders cocriado com gerentes gerais de Bourbon Hotéis \& Resorts entrevistados, existem diversos intermediários entre a rede e as empresas interessadas em eventos corporativos, dentre eles as Empresas de Marketing de Destinações e Convention \& Visitors Bureau que, assim como a rede hoteleira, também se interessa em captar eventos para a destinação a qual promove. Bem como as agências gestoras de viagens corporativas, que comercializam pacotes de turismo cuja atração principal seriam esses eventos, em especial aqueles realizados por associações de classe, que aceitam a participação de outros profissionais, que não de uma única empresa.

Observou-se também que stakeholders indiretamente ligados às atividades de turismo de negócios exercem importante influência na satisfação e experiência de estada de turistas de negócios nas cidades visitadas, tais como a receptividade da população local, e os serviços de infraestrutura de responsabilidade de órgãos públicos de governança, em especial aqueles ligados ao acesso às cidades como aeroportos, e rodoviárias, ou de mobilidade urbana como transporte público. 
Ratifica-se parcialmente a proposição de número 3, "apenas o relacionamento com stakeholders envolvidos na realização dos eventos, são considerados fatores de competitividade", pois como abordado também na proposição de número 2 , o relacionamento com stakeholders intermediários de eventos corporativos realmente beneficia um hotel, porém, não é considerado o único grupo que influencia ou é influenciado por objetivos e ações de hospedagem de eventos deste. Outros stakeholders, como os já citados órgãos públicos de governança e comunidade local, quando engajados com a atividade turística, também são diferenciais competitivos, porém, da destinação onde o hotel esteja instalado, mas que afeta positivamente ao mesmo.

Outros stakeholders envolvidos com eventos corporativos, considerados estratégicos para a competitividade, são os anfitriões do hotel para recepção e acolhimento de hóspedes e participantes, bem como estar a disposição desses participantes nos momentos necessários. Instituições de ensino para preparação e qualificação de colaboradores são igualmente considerados, dado que são parceiros essenciais para que os serviços se mantenham na qualidade adequada.

Contudo, o relacionamento com stakeholders não é considerado o único fator que contribui para a atração de eventos para um hotel, destacando-se também seus programas de manutenção de sua estrutura, equipamentos, bem como a flexibilidade de suas salas para eventos de diversos portes, passando segurança ao parceiro de que seu evento será um sucesso.

Por fim, espera-se, por meio deste estudo, contribuir com os entendimentos acadêmicos acerca dos efeitos da compreensão da teoria de stakeholders de Freeman (1984), como fator de competitividade por meio da gestão do relacionamento com estes, baseando-se nos princípios da hospitalidade na atração de eventos corporativos, gerando contatos de confiança e benefícios financeiros tanto a um hotel quanto aos demais relacionados a este.

Sugere-se, para estudos, a utilização de outras redes hoteleiras, sendo duas ou mais em meio estudo, de modo que seja possível realizar comparações quando suas estratégias de relacionamento com stakeholders, bem como de que modo estes compreendem a hospitalidade. 


\section{REFERÊNCIAS}

ARANHA, C.; MIGUEL, C. Negócios lucrativos no mercado de eventos corporativos. São Paulo: Editora Abril, 2013. Disponível em: $<$ http://exame.abril.com.br/revista-exame-pme/edicoes/0057/noticias/negocioslucrativos-no-mercado-de-eventos-corporativos?page=3>. Acesso em: 05/05/2014.

BOURBON. Bourbon Hotéis e Resorts: Nossos hotéis e resorts. 2016a. Disponível em: <http://www.bourbon.com.br/pt/hoteis-e-resorts-pt/> Acesso em: 10/07/2014.

BOURBON. Bourbon Hotéis e Resorts: Bourbon eventos. 2016b. Disponível em: <http://www.bourbon.com.br/eventos-pt/> Acesso em: 13/07/2014.

BOURBON. Bourbon Hotéis e Resorts: Bourbon Conmebol Assunção Convention Hotel. 2016c. Disponível em: <http://www.bourbon.com.br/hotel/upscale$\mathrm{pt} /$ convention-hotel-pt/bourbon-conmebol-assuncao-convention-hotel/> Acesso em: $11 / 09 / 2014$.

BRAGA, D. C. Turistas de Negócios na Cidade de São Paulo: Um estudo de demanda segmentada. Turismo em Análise, v. 17, n. 1. p. 85-107, maio. 2006. Disponível em: <http://www.revistas.usp.br/rta/article/download/68278/70794>. Acesso em: $11 / 09 / 2014$

BRASIL. Ministério do Turismo. Brasil, avanços no turismo de negócios e eventos. 2015. Disponível em: <http://www.turismo.gov.br/ultimas-noticias/1420-brasilavancos-no-turismo-de-negocios-e-eventos.html>. Acesso em: 29/06/2016.

BRONZE JÚNIOR, J. C. F; VELOSO E SOUSA, C.; LARA, J. E.; FAGUNDES, A. F. A.; SAMPAIO, D. O. O setor hoteleiro e o marketing de relacionamento: Um estudo de caso na cidade de Belo Horizonte - Minas Gerais, Brasil. Revista Turismo \& Sociedade. Curitiba, v. 5, n. 2, p. 489-506, out. 2012.

CAMARGO, L. O. L. Hospitalidade. São Paulo: Aleph, 2004.

FREDERICO, P. R. P.; FREDERICO, R. L. R.; OLIVEIRA, V. A. Fidelização e qualidade dos serviços por meio da hospitalidade e da comunicação. In: XXVIII CONGRESSO BRASILEIRO DE CIÊNCIAS DA COMUNICAÇÃO, Rio de Janeiro, RJ, Brasil. Anais... Rio de Janeiro, 2005, p. 1-7. Disponível em: <http://www.portcom.intercom.org.br/pdfs/89312149397260047483027203529236622 181.pdf>. Acesso em: 12/09/2014.

FREEMAN, R. E. Strategic Management: a stakeholder approach. Minnesota: Pitman, 1984.

GOTMAN, A. Le sens de I'hospitalité: essai sur les fondements sociaux de l'accueil de l'autre. Paris: Presses Universitaires de France, 2001. 
GOTMAN, A. O comércio da hospitalidade é possível? Revista hospitalidade, São Paulo, v. 6, n. 2, p. 3-27, dezembro, 2009. Disponível em: <https://www.revhosp.org/hospitalidade/article/view/311>. Acesso em: 11/09/2014.

GUIZI, A. A.; SANTOS, A. F. L.; WADA, E. K. Hotelaria e stakeholders: Competitividade em eventos corporativos - Estudo de caso sobre a rede Bourbon de Hotéis \& Resorts. In: XI SEMINÁRIO DA ASSOCIAÇÃO NACIONAL DE PESQUISA E PÓS-GRADUAÇÃO EM TURISMO (ANPTUR), 2014. Anais... do XI Seminário ANPTUR. São Paulo: Aleph, 2014.

H2FOZ. Rede Bourbon de Hotéis \& Resorts comemora 50 anos de história. 2013. Disponível em: <http://www.h2foz.com.br/noticia/rede-bourbon-de-hoteis-resortscomemora-50-anos-de-historia>. Acesso em: 18/06/2014.

JUNQUEIRA, R. R.; WADA, E. K. A hospitalidade enquanto competência essencial na gestão do relacionamento com o cliente: Gran Estanplaza, São Paulo. In: VII SEMINÁRIO DA ASSOCIAÇÃO NACIONAL DE PESQUISA E PÓSGRADUAÇÃO EM TURISMO (ANPTUR), 2010. São Paulo. Anais... São Paulo: Aleph, 2010. Disponível em:

<http://www.academia.edu/download/35522550/a_hospitalidade_enquanto_competenci a_essencial_na.ANPTUR2010.pdf>. Acesso em: 13/05/2014.

KIM, W. C.; MAUBORGNE, R. A estratégia do oceano azul: Como criar novos mercados e tornar a concorrência irrelevante. Rio de Janeiro: Elsevier, 2005.

LASHLEY, C. Towards a theoretical understanding. In: LASHLEY, C; MORRISON, A. (ed.) In search of hospitality. Oxford: Butterworth Heinemann, 2000. p. 01-17.

LAVILLE, C.; DIONE, J. A construção do saber: Manual de metodologia da pesquisa em ciências humanas. Porto Alegre: Artmed; Belo Horizonte: Editora UFMG, 1999.

NAKANE, A. M. Locações de espaços para eventos em meios de hospedagem. In: FERREIRA, R. S.; WADA, E. K. (org.) Eventos uma alavanca de negócios: Como e porque implantar PEGE. São Paulo: Aleph, 2010. p. 151-161.

OLIVEIRA, N. M.; FONTANA, R. F. Eventos na hotelaria: Um recorte sobre as confraternizações empresariais de final de ano nos meios de hospedagem de Foz do Iguaçu/PR. In: $5^{\circ}$ CONGRESSO LATINO-AMERICANO DE INVESTIGAÇÃO TURÍSTICA. Anais... São Paulo: USP, 2012.

PALUMBO, L. Seleção brasileira sob os cuidados da rede Bourbon, na Granja Comary. São Paulo e Rio de Janeiro: Folha Dirigida, 2016. Disponível em: $<$ http://www.mercadoeeventos.com.br/noticias/hotelaria/\%E2\%80\%8Bselecaobrasileira-sob-os-cuidados-da-rede-bourbon-na-granja-comary/>. Acesso em: 08/07/2016. 
PRAHALAD, C. K.; HAMEL, G. Competindo pelo futuro: Estratégias inovadoras para obter o controle do seu setor e criar os mercados de amanhã. Rio de Janeiro: Elsevier, 2005.

REVISTA HOTÉIS. Entrevista com Alceu Vezozzo Filho - Presidente da Bourbon Hotéis \& Resorts, 2013. Disponível em: <http://revistahoteis.com.br/materias/5Entrevista/11527-Entrevista-com-Alceu-Vezozzo-Filho-Presidente-da-Bourbon-HoteisResorts>. Acesso em: 05/10/2014.

SCHULZE, C. A. O turismo de negócios e eventos em Cascavel (Paraná, Brasil): oportunidade para expansão e consolidação do segmento na cidade. Revista Turismo \& Sociedade. Curitiba, v. 6, n. 2, p. 345-363, abril de 2013. Disponível em: $<$ http://revistas.ufpr.br/turismo/article/view/30254>. Acesso em: 10/05/2014.

SELWYN, T. Uma antropologia da hospitalidade. In: LASHLEY, C.; MORRISON, A. (ed) Em busca da hospitalidade: Perspectivas para um mundo globalizado. Barueri: Manole, 2004. p. 25-52

STEFANINI, C. J.; YAMASHITA, A.; SOUSA, R. B. M. Turismo de negócios: O uso da análise fatorial como instrumento de identificação dos valores para os viajantes a negócios. Revista de Investigación en Turismo y Desarrollo Local. v. 5, n. 12. Junho de 2012. Disponível em: < http://www.eumed.net/rev/turydes/12/sys.pdf $>$. Acesso em: $13 / 03 / 2014$.

VAN RIEL, C. B. M. Reputação: O valor estratégico do engajamento de stakeholders. Rio de Janeiro: Elsevier, 2013.

WADA, E. K. Domínios de hospitalidade de Lashley e possíveis aplicações na hotelaria. In: IV SEMINÁRIO DA ASSOCIAÇÃO BRASILEIRA DE PESQUISA E PÓS-GRADUAÇÃO EM TURISMO - ANPTUR, São Paulo, SP, Brasil. Anais... São Paulo, 2007.

Turismo de negócios: Viagens corporativas, eventos e incentivos. In: PANOSSO NETTO, A.; ANSARAH, M. G. d. R. Segmentação do mercado turístico: Estudos, produtos e perspectivas. Barueri: Manole, 2009. p. 213-226

WOODRUFF, R. B. Customer value: The next source for competitive advantage. Journal of the academy of marketing science, v. 25, n. 2, p. 139-153. Disponível em: <http://link.springer.com/article/10.1007/BF02894350>. Acesso em: 08/07/2016.

YIN, R. K. Estudo de caso: Planejamento e Métodos. Porto Alegre: Bookman, 2010.

Recebido em: 03-08-2015.

Aprovado em: 02-09-2015. 